\title{
Molecular detection and genetic characterization of infectious laryngotracheitis virus in poultry in Myanmar
}

\author{
Zhiyuan Yang ${ }^{1,2}$, Shiro Murata ${ }^{1 *}$ D , Sotaro Fujisawa ${ }^{1}$, Masaki Takehara', Ken Katakura' ${ }^{1}$, Myint Myint Hmoon ${ }^{3}$,
} Shwe Yee Win $^{3}$, Saw Bawm ${ }^{3}$, Satoru Konnai ${ }^{1}$ and Kazuhiko Ohashi ${ }^{1}$

\begin{abstract}
Background: Avian infectious laryngotracheitis (ILT) is a highly contagious viral disease that causes severe economic losses to the poultry industry worldwide. In Southeast Asian countries, including Myanmar, poultry farming is a major industry. Although it is known that infectious respiratory pathogens, including infectious laryngotracheitis virus (ILTV), are a major threat to poultry farms, there are no data currently available on the epidemiology of ILTV in Myanmar. Therefore, in this study, we conducted a molecular detection of ILTV in 20 poultry farms in Myanmar.
\end{abstract}

Results: Of the 57 tested oropharyngeal swabs, 10 were positive for ILTV by polymerase chain reaction of a $647 \mathrm{bp}$ region of the thymidine kinase (TK) gene, giving a prevalence of ILTV of 17.5\% (10/57). Further sequencing analysis of infected cell protein 4 (ICP4) gene and glycoprotein $B, G$, and J ( $g B, g G$, and $g$ ) genes indicated that these isolates were field strains. Phylogenetic analysis revealed that the Myanmar strains clustered together in a single branch and were closely related to other reference strains isolated from Asian countries.

Conclusions: This study demonstrated the presence of ILTV in poultry farms in Myanmar. The genetic characterization analysis performed provides the fundamental data for epidemiological studies that monitor circulating strains of ILTV in Myanmar.

Keywords: Infectious laryngotracheitis virus, Molecular detection, Myanmar, Poultry, Phylogeny

\section{Background}

Infectious laryngotracheitis (ILT) is an acute and highly contagious viral disease that affects adult chickens, which is characterized by inflammation and hemorrhage of the larynx and trachea [1]. The etiological agent is Gallid alphaherpesvirus 1 (GaHV-1), a member of the family Herpesviridae, subfamily

\footnotetext{
* Correspondence: murata@vetmed.hokudai.ac.jp

${ }^{1}$ Faculty of Veterinary Medicine, Hokkaido University, Sapporo, Japan

Full list of author information is available at the end of the article
}

Alphaherpesvirinae, genus Iltovirus, and is commonly called infectious laryngotracheitis virus (ILTV) [2]. Acute ILTV infection can cause high morbidity and mortality in chickens while chronic infection is characterized by decreased growth rates and reduced egg production [3], thus causing serious economic losses to the poultry industry worldwide.

In Southeast Asian countries, including Myanmar, poultry farming is a major industry. Myanmar, which is located in the northeast edge of Southeast Asia, is the

C C The Author(s). 2020 Open Access This article is licensed under a Creative Commons Attribution 4.0 International License, which permits use, sharing, adaptation, distribution and reproduction in any medium or format, as long as you give appropriate credit to the original author(s) and the source, provide a link to the Creative Commons licence, and indicate if changes were made. The images or other third party material in this article are included in the article's Creative Commons licence, unless indicated otherwise in a credit line to the material. If material is not included in the article's Creative Commons licence and your intended use is not permitted by statutory regulation or exceeds the permitted use, you will need to obtain permission directly from the copyright holder. To view a copy of this licence, visit http://creativecommons.org/licenses/by/4.0/ The Creative Commons Public Domain Dedication waiver (http://creativecommons.org/publicdomain/zero/1.0/) applies to the data made available in this article, unless otherwise stated in a credit line to the data. 
largest country in the mainland of Southeast Asia. Along with the increasing demand for sustainable, locally produced, and safe poultry products for Myanmar consumers, the prevention and control of infectious diseases in poultry has become increasingly important.

Currently, immunization is the principal tool used to control ILTV [4]. The two types of live-attenuated vaccines used are derived from either chicken embryo-origin (CEO) vaccine strains [5], which are attenuated by serial-passage in embryonated eggs, or tissue culture-origin (TCO) vaccine strains [6], which are obtained by multiple passages in tissue culture. However, the vaccine strains can revert to virulence after passages in susceptible birds [7]. Menendez et al indicated that live-attenuated vaccine-related isolates may have contributed to ILT outbreaks worldwide [8]. ILT still occurs frequently and causes significant economic losses in the chicken industry of many countries including Italy [9], Korea [10], Australia [11], and China [12], despite the preventative and biosecurity measures that are in place. It is reported that some ILTV isolates involved in recent ILT outbreaks in Italy might have originated from CEO vaccines [13]. Meanwhile, virulent field strains genetically related to CEO vaccines have also been detected in Korea [10]. Another reason leading to that might be related with the recombination events between attenuated ILTV vaccines resulting in more virulent or transmissible field strains [14]. Two newly emerged genotypes of viruses have been proven to be a result of the recombination between a previously existing Australian vaccine strain (SA2 and A20) and a vaccine (Serva) introduced into the country in 2007 [14, 15]. Therefore, investigating ILTV strains in circulation in endemic areas is not only useful to evaluate vaccine efficacy, but also necessary to identify the etiology of disease outbreaks in the poultry population.

Since some ILTV field strains are closely related to the vaccine-derived strains, most studies have used polymerase chain reaction-restriction fragment length polymorphism (PCR-RFLP) or sequencing a single target region to discriminate between them [9]. However, sequencing multiple target regions would be more useful to better characterize circulating strains and enable more reliable discrimination between ILTV field and vaccinederived strains [16].

To date, the avian influenza and Newcastle disease have been reported in Myanmar [17-19]. More recently, the genetic characteristics of other respiratory pathogens, including Mycoplasma gallisepticum, Mycoplasma synoviae, and infectious bronchitis virus, have also been investigated [20]. However, to date, there is no scientific report on the epidemiology of ILTV in Myanmar, although some clinical signs suggestive of respiratory pathogen infections have been observed.

In this study, therefore, we aimed to assess the prevalence of ILTV in chickens from major Myanmar poultry farms using molecular detection techniques, and perform Sanger sequencing of the isolates to monitor the strains in circulation in this region.

\section{Results}

Molecular detection of ILTV in poultry farms of Myanmar Chicken swab samples $(n=171)$ were collected from 20 poultry farms in Myanmar; three samples were pooled and a total of 57 pools were subjected to the DNA extraction and PCR targeting the thymidine kinase $(T K)$ gene. Out of 57 pools collected from different farms, 10 (17.5\%) were positive for ILTV (Table 1). The DNA positive control extracted from the ILTV attenuated vaccine showed amplification with a band at the expected size $(647 \mathrm{bp})$ after gel electrophoresis. The nucleotide sequences of the amplified target region were further confirmed by sequencing, and no difference in the sequences between the Myanmar samples and vaccine strains, TCO and CEO were observed (Supplemental Table 1). Of note, most of the positive samples had been collected from the Yangon area during the wet season (May) (Table 1).

\section{Characterization of the ICP4, $g B, g G$, and $g J$ genes}

To genetically characterize the ILTV isolates, the ICP4, $g B, g G$, and $g J$ genes were partially amplified in the 10 field samples that were positive for the TK gene. Six samples from different farms (Farm Ma-2, Farm Ya-1, Farm Ya-2, Farm Ya-4, Farm Ya-5, and Farm Ya-8) were selected for sequence analysis; five of the six field samples showed $100 \%$ identity with each other although some single nucleotide polymorphisms (SNPs) were also observed in $I C P 4, g B, g G$, and $g J$ genes when compared to reference sequences from GenBank (Tables 2 and 3). For the ICP4 gene, two fragments located at positions 181-868 and 3645-4268 were used to differentiate ILTV field isolates from live-attenuated vaccine strains as described previously [21]. As shown in Table 2, a 12-bp deletion, two substitutions in the ICP4 gene fragment 1 , and five point mutations in the ICP4 gene fragment 2 were observed.

In this study, a non-synonymous SNP at position 1931 in the $g B$ genes from the field isolates, except for Farm Ya-5, was cytosine, was similar to what is seen in most field strains, whereas the one from most vaccine strains was coded for thymine (Table 3). This point mutation led to an isoleucine-to-threonine substitution at position 644 (I644T) in the $g B$ protein of field strains. Similarly, some SNPs were observed in 
Table 1 Details of the distribution of ILTV

\begin{tabular}{|c|c|c|c|c|}
\hline Sampling area & Farm ID & Date & No. of chickens & No. of detected/No. of tested ${ }^{\text {a }}(\%)$ \\
\hline \multirow[t]{5}{*}{ Mandalay } & $\mathrm{Ma}-1$ & Feb. 10, 2018 & 12 & $0 / 4(0.0)$ \\
\hline & Ma-2 & Feb. 10, 2018 & 9 & 1/3 (33.3) \\
\hline & Ma-3 & Feb. 10, 2018 & 9 & $0 / 3(0.0)$ \\
\hline & Ma-4 & Feb. 11, 2018 & 9 & $0 / 3(0.0)$ \\
\hline & Ma-5 & Feb. 11, 2018 & 9 & $0 / 3(0.0)$ \\
\hline \multirow[t]{5}{*}{ Pyin Oo Lwin } & Py-1 & Feb. 12, 2018 & 9 & $0 / 3(0.0)$ \\
\hline & Py-2 & Feb. 12, 2018 & 9 & $0 / 3(0.0)$ \\
\hline & Py-3 & Feb. 12, 2018 & 9 & $0 / 3(0.0)$ \\
\hline & Py-4 & Feb. 12, 2018 & 9 & $0 / 3(0.0)$ \\
\hline & Py-5 & Feb. 12, 2018 & 9 & $0 / 3(0.0)$ \\
\hline \multirow[t]{10}{*}{ Yangon } & Ya-1 & May 28, 2018 & 9 & $2 / 3(66.7)$ \\
\hline & Ya-2 & May 28, 2018 & 6 & $2 / 2(100)$ \\
\hline & Ya-3 & May 28, 2018 & 6 & $0 / 2(0.0)$ \\
\hline & Ya-4 & May 28, 2018 & 6 & $1 / 2(50.0)$ \\
\hline & Ya-5 & May 29, 2018 & 9 & $3 / 3(100)$ \\
\hline & Ya-6 & May 29, 2018 & 6 & $0 / 2(0.0)$ \\
\hline & Ya-7 & May 29, 2018 & 9 & 0/3 (0.0) \\
\hline & Ya-8 & May 29, 2018 & 9 & 1/3 (33.3) \\
\hline & Ya-9 & May 29, 2018 & 9 & $0 / 3(0.0)$ \\
\hline & Ya-10 & May 29, 2018 & 9 & 0/3 (0.0) \\
\hline Total & & & & 10/57 (17.5) \\
\hline
\end{tabular}

${ }^{a}$ Three oropharyngeal swab samples were pooled and analyzed

the $g J$ and $g G$ genes of ILTV. The sequences of the $g J$ gene fragments from the Myanmar isolates, except for Farm Ya-5, were identical to those from a China/ K317 vaccine-derived strain and a Korean field strain, whereas the sequences of the $g G$ gene fragments from the Myanmar isolates were unique (Table 3). Moreover, a point mutation in position 102 in the $g G$ gene led to a non-synonymous amino acid substitution (Glutamic acid-to-Aspartic acid substitution at position 34, E34D). Five distinct haplotypes were defined according to the specific changes in select nucleotide positions of the $g J$ gene [1]. Sequence analysis in the present study showed that haplotype 2 was the predominant type (Supplemental Table 2).

\section{Phylogenetic analysis of the ICP4, gB, gG and gJ genes}

Phylogenetic analysis based on the ICP4 and gB genes showed that five out of six isolates obtained in this study clustered together and were closely related to reference strains, including from Asian countries (Fig. 1a and b). In contrast, the phylogenetic tree constructed using the $g G$ and $g J$ genes showed that the five isolates in Myanmar formed into a distinct cluster, separate from other reference strains deposited in the GenBank database (Fig. 1c and d).

\section{Discussion}

Although ILTV causes less mortality than the highly pathogenic avian influenza virus and Newcastle disease, its impact on avian productivity has caused significant economic losses to the poultry industry worldwide [22]. However, no scientific data on ILTV surveillance in poultry farms in Myanmar has been available until now. In this study, we investigated the presence of ILTV in Myanmar among 20 poultry farms in Myanmar using PCR targeting the TK gene and we detected ILTV in six farms that were located in southern Myanmar.

Molecular characterization of ILTV is required to differentiate between field and vaccine strains [21, 23, 24]. ICP4 is responsible for the regulation of gene expression early in infection [25] and has been proposed as a potential differentiation marker due to differences in this gene in the wild-type and vaccine strains [26]. The sequences from the isolates in Myanmar in the present study had a $12 \mathrm{bp}$-deletion at positions 259-270 in the ICP4 gene fragment 1; this deletion is typically not present in the TCO vaccine strains. In addition, the nucleotide sequences of ICP4 gene fragment 2 in the isolates showed distinct differences from TCO vaccine strain sequences. According to the 
Table 2 Nucleotide sequence alignment of ICP4 gene fragments from the isolates in Myanmar, vaccine strains and other ILTV strains

\begin{tabular}{|c|c|c|c|c|c|c|c|c|c|c|c|c|c|c|}
\hline \multirow[t]{3}{*}{ Name of strains } & \multicolumn{14}{|c|}{ Nucleotide position from ATG ${ }^{a}$} \\
\hline & \multicolumn{8}{|c|}{ ICP4 fragment 1 (positions 181 to 868 ) } & \multicolumn{6}{|c|}{ ICP4 fragment 2 (positions 3645 to 4268 ) } \\
\hline & $259-270$ & 438 & 456 & 594 & 597 & 611 & 795 & 811 & 3879 & 3905 & 3957 & 3981 & 4012 & 4047 \\
\hline Farm Ya-1 & $* \mathrm{~b}$ & A & A & C & A & * & G & G & A & $\mathrm{T}$ & C & C & A & A \\
\hline Farm Ya-2 & * & $-c$ & - & - & - & * & - & - & - & - & - & - & - & - \\
\hline Farm Ya-4 & * & - & - & - & - & * & - & - & - & - & - & - & - & - \\
\hline Farm Ya-5 & * & - & - & - & - & * & - & - & - & - & - & - & - & - \\
\hline Farm Ya-8 & * & - & - & - & - & * & - & - & - & - & - & - & - & - \\
\hline Farm Ma-2 & * & - & - & - & - & * & - & - & - & - & - & - & - & - \\
\hline MF417811_USA/14.939 & * & - & - & - & - & * & - & - & - & - & - & - & - & - \\
\hline JN542533_USA/1874C5 & GCGGCCCAAGAC & G & G & * & G & G & A & A & - & C & $\mathrm{T}$ & - & - & G \\
\hline JN542534_USA/USDA & GCGGCCCAAGAC & G & - & - & G & * & - & - & - & C & $\mathrm{T}$ & $\mathrm{T}$ & G & G \\
\hline JN542535_USA/81658 & GCGGCCCAAGAC & G & - & - & G & * & - & - & - & C & $\mathrm{T}$ & $\mathrm{T}$ & G & G \\
\hline JN542536_USA/63140 & * & - & - & - & - & * & - & - & - & - & - & - & - & - \\
\hline JN804827_Australia/CL9 & * & - & - & - & - & * & - & - & - & - & - & - & - & - \\
\hline JX646898_Australia/V1-99 & * & - & - & - & - & * & - & - & - & C & - & - & - & G \\
\hline JN596963_Australia/A20 vaccine & GCGGCCCAAGAC & G & G & - & G & * & A & A & - & C & $\mathrm{T}$ & - & - & G \\
\hline HQ630064_Australia/Serva vaccine & * & - & - & - & - & * & - & - & - & - & - & - & - & - \\
\hline JX458822_China/LJS09 & * & - & - & - & - & * & - & - & - & - & - & - & - & - \\
\hline JX458823_China/WG & * & - & - & - & - & * & - & - & $\mathrm{T}$ & - & - & - & - & - \\
\hline JX458824_China/K317 vaccine & * & - & - & - & - & * & - & - & $\mathrm{T}$ & - & - & - & - & - \\
\hline MH937564_Korea & * & - & - & - & - & * & - & - & - & - & - & - & - & - \\
\hline MH937565_Korea & * & G & G & - & G & * & A & A & - & - & - & - & - & - \\
\hline MH937566_Korea & * & - & - & - & - & * & - & - & - & - & - & - & - & - \\
\hline JN580312/TCO vaccine-IVAX & GCGGCCCAAGAC & G & - & - & G & * & - & - & - & C & $\mathrm{T}$ & $\mathrm{T}$ & G & G \\
\hline JN580313/CEO vaccine-TRVX & * & - & - & - & - & * & - & - & - & - & - & - & - & - \\
\hline NC006623_USA & GCGGCCCAAGAC & G & G & * & G & G & A & A & - & C & $\mathrm{T}$ & - & - & G \\
\hline
\end{tabular}

${ }^{\mathrm{a}}$ The ICP4 gene sequence with Genbank accession number NC_006623 was taken as a reference

$b_{*}$ Deletions within the sequences

${ }^{c}$-Regions where the sequences are identical to those of Farm Ya-1

local veterinarians from Myanmar poultry farms, TCO vaccine strain is used to prevent the incidence of ILT in poultry farms that we visited. Therefore, the isolates detected in the present study appear to be field strains.

Glycoprotein B encoded by $U L 27$ gene is one of the major proteins in ILTV, playing a fundamental role in virus attachment to target cells and cell entry [27]. According to our data, the point mutation at position 1931 in the $g B$ gene was found in most virulent and vaccine strains (including TCO and CEO strains). Gracía et al. also reported that the codon at position 1931 in the $g B$ gene from most field strains was coded for cytosine, whereas the one from most vaccine strains was coded for thymine [28]. Therefore, the SNP at position 1931 in the $g B$ gene could act as a good differentiation marker for field and vaccine strains $[9,28]$. In contrast, the isolate from Farm Ya-
5 showed similarity to the vaccine strains as well as a few field isolates.

gJ protein is a major viral antigen and plays an important role during egress of ILTV [29]. Craig et al. [1] compared seven different partial fragments of some ILTV genes ( $T K, g D, g G, g B, g C, g J$, and ICP4). The gJ sequence was the most informative segment to discriminate between field and vaccine strains [1], and the gJ sequence of the isolates in the present study indicated haplotype 2 out of five distinct haplotypes.

Sequencing analysis of the $g G$ gene has also been used to characterize ILTV isolates [30]. By comparing the partial sequence of $g G$ genes with those of other reference strains, a non-synonymous substitution (Glu-toAsp) at position 34 was identified in the $g G$ gene of field isolates from this study. To our knowledge, no other studies have reported this mutation in the $g G$ gene of either field or vaccine strains. Further investigation of 
Table 3 Nucleotide sequence alignment of $\mathrm{gB}, \mathrm{gG}$ and $\mathrm{gJ}$ gene fragments from the isolates in Myanmar, vaccines strains and other ILTV strains

\begin{tabular}{|c|c|c|c|c|c|c|c|c|c|c|c|c|c|}
\hline \multirow[t]{3}{*}{ Name of strains } & \multicolumn{13}{|c|}{ Nucleotide position from ATG $^{a}$} \\
\hline & \multirow{2}{*}{$\begin{array}{l}\text { gB } \\
1931\end{array}$} & \multicolumn{5}{|l|}{ gG } & \multicolumn{7}{|l|}{ gJ } \\
\hline & & 66 & 102 & 173 & 292 & 344 & 461 & 484 & 765 & 777 & 832 & 878 & 894 \\
\hline Farm Ya-1 & C & G & C & $T$ & C & $\mathrm{T}$ & A & C & C & C & A & $T$ & G \\
\hline Farm Ya-2 & $-\mathrm{b}$ & - & - & - & - & - & - & - & - & - & - & - & - \\
\hline Farm Ya-4 & - & - & - & - & - & - & - & - & - & - & - & - & - \\
\hline Farm Ya-5 & $\mathrm{T}$ & - & G & - & - & - & - & - & - & $\mathrm{T}$ & - & - & - \\
\hline Farm Ya-8 & - & - & - & - & - & - & - & - & - & - & - & - & - \\
\hline Farm Ma-2 & - & - & - & - & - & - & - & - & - & - & - & - & - \\
\hline MF417811_USA/14.939 & - & A & G & - & - & - & - & - & - & $\mathrm{T}$ & - & - & - \\
\hline JN542533_USA/1874C5 & - & - & G & - & A & - & - & - & $\mathrm{T}$ & $\mathrm{T}$ & - & - & - \\
\hline JN542534_USA/USDA & - & A & G & - & - & - & - & $\mathrm{T}$ & - & $\mathrm{T}$ & - & C & - \\
\hline JN542535_USA/81658 & $\mathrm{T}$ & A & G & - & - & - & - & $\mathrm{T}$ & - & $\mathrm{T}$ & - & C & - \\
\hline JN542536_USA/63140 & - & A & G & - & - & - & - & - & - & $\mathrm{T}$ & - & - & - \\
\hline JN804827_Australia/CL9 & - & A & G & - & - & - & - & - & - & $\mathrm{T}$ & - & - & - \\
\hline JX646898_Australia/N1-99 & - & - & G & G & A & G & - & - & $\mathrm{T}$ & $\mathrm{T}$ & - & - & - \\
\hline JN596963_Australia/A20 vaccine & - & - & G & G & A & G & - & - & $\mathrm{T}$ & $\mathrm{T}$ & - & - & - \\
\hline HQ630064_Australia/Serva vaccine & $\mathrm{T}$ & A & G & - & - & - & - & - & - & $\mathrm{T}$ & - & - & - \\
\hline JX458822_China/LJS09 & $\mathrm{T}$ & A & G & - & - & - & - & - & - & $\mathrm{T}$ & - & - & - \\
\hline JX458823_China/WG & - & - & G & G & A & G & - & - & $\mathrm{T}$ & $\mathrm{T}$ & - & - & - \\
\hline JX458824_China/K317 vaccine & $\mathrm{T}$ & A & G & - & - & - & - & - & - & - & - & - & - \\
\hline MH937564_Korea & $\mathrm{T}$ & A & G & - & - & - & - & - & - & $\mathrm{T}$ & - & - & - \\
\hline MH937565_Korea & - & - & G & G & A & G & - & - & $\mathrm{T}$ & $\mathrm{T}$ & - & - & - \\
\hline MH937566_Korea & $\mathrm{T}$ & A & G & - & - & - & - & - & - & - & - & - & - \\
\hline JN580312/TCO vaccine-IVAX & $\mathrm{T}$ & A & G & - & - & - & - & $\mathrm{T}$ & - & $\mathrm{T}$ & - & C & - \\
\hline JN580313/CEO vaccine-TRVX & $\mathrm{T}$ & A & G & - & - & - & - & - & - & - & - & - & - \\
\hline NC006623_USA & $\mathrm{T}$ & A & G & - & - & - & - & $\mathrm{T}$ & - & $\mathrm{T}$ & - & C & - \\
\hline
\end{tabular}

${ }^{\mathrm{a}}$ The sequence of each gene ( $\mathrm{gB}, \mathrm{gG}$ and $\mathrm{gJ}$ genes) with Genbank accession number NC_006623 was taken as a reference

${ }^{b}$-Regions where the sequences are identical to those of Farm Ya-1

ILTV strains circulating in the other regions of Myanmar is therefore necessary. Furthermore, since ILTV gG is a known virulence factor that can bind chemokines with high affinity and inhibit leukocyte chemotaxis $[31,32]$, the biological significance of this amino acid substitution (Glu 34 Asp) in the $g G$ gene requires further investigation to determine whether it impacts on the pathogenicity of ILTV.

In the present study, ILTV was mainly detected in the Yangon farms (southern area of the country). All the Yangon samples were collected in May, which is the wet season in Myanmar. In contrast, the Mandalay and Pyin Oo Lwin samples were collected in February, which is the dry season, and almost all were negative for ILTV. The duration of sunshine in the dry season is longer than during the wet season in Myanmar. Since the ultraviolet rays in sunlight might affect the activity of ILTV, it is possible that ILTV transmission may be limited during the dry season, thus partially explaining why most positive samples were detected from Yangon farms and very few from Mandalay and Pyin Oo Lwin farms. Therefore, future studies should ensure that sampling is conducted during similar seasons to ensure accurate representation of the circulating ILTV strains in Myanmar.

Phylogenetic analyses of the ICP4 and $g B$ genes indicated that the Myanmar ILTV isolates were closely related to ILTV reference strains including Asian strains, especially three Korean field isolates, which most likely originated from the Serva vaccine strain [10]. These results suggest that the ILTV isolates detected in poultry farms in Myanmar might be similar to those circulating in neighboring Asian countries, and they have perhaps been endemic for a certain time given the presence of the unique mutations in the $g G$ and $g J$ genes. According to the phylogenetic 


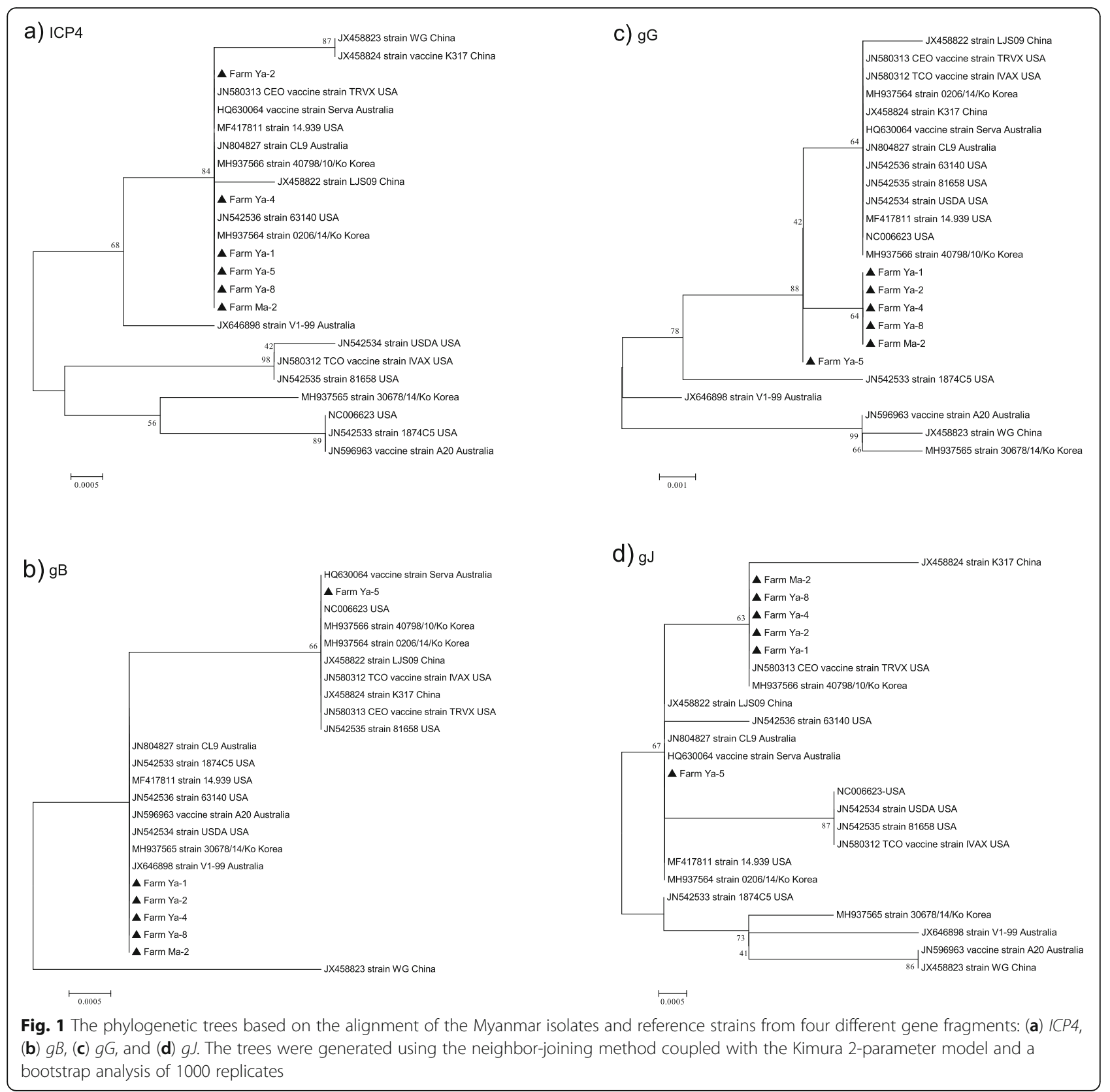

analysis comparing the $g B$ and $g G$ gene sequences obtained in this study and those previously published in Genbank, five Myanmar isolates clustered into separate branches belonging to the CEO vaccine and TCO vaccine strains. In contrast, phylogenetic analysis using the $g J$ and ICP4 gene sequences revealed that these isolates clustered together with $\mathrm{CEO}$ vaccine. In a previous study by Oldoni et al. [33], three isolates could only be differentiated from the CEO vaccine by the analysis of glycoprotein $\mathrm{M}$ gene. Meanwhile, molecular techniques have identified live-attenuated vaccines as one of the main causes of ILTV outbreaks worldwide [8]. CEO vaccine has been banned in Argentina for more than 10 years due to its associated reversion to virulence [1]. Shehata et al. [34] also isolated three highly pathogenic CEO-like field strains and suggested that $\mathrm{CEO}$ vaccine strains could increase in virulence after bird-to-bird passages causing severe outbreaks in susceptible birds. It is more likely that the ILTV isolates circulating in poultry farms in Myanmar originated from CEO-like viruses. However, such a hypothesis requires further periodical surveillance using larger sample sizes and sequence analysis based on additional ILTV genomic regions. 


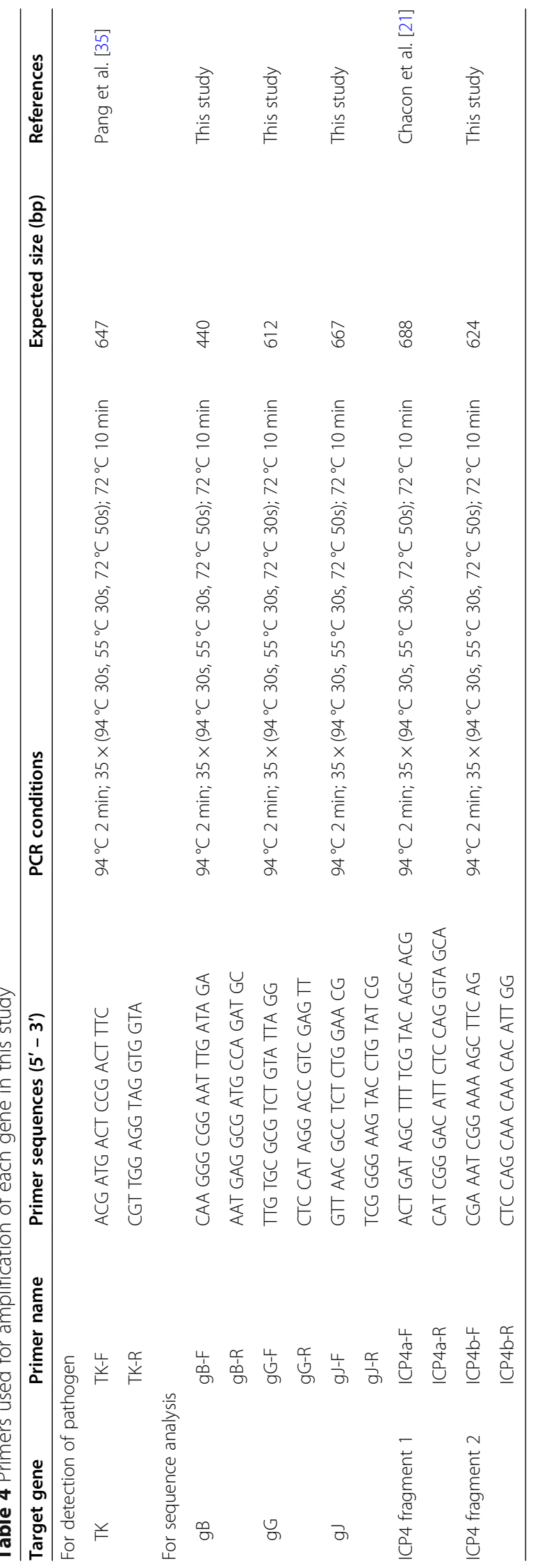


Table 5 Reference strains used in this study

\begin{tabular}{llll}
\hline Virus strains & Origin & Country & Accession \\
\hline 14.939 & Field strain & U.S. & MF417811 \\
1874C5 & Field strain & U.S. & JN542533 \\
USDA & Challenge strain & U.S. & JN542534 \\
81,658 & Field strain & U.S. & JN542535 \\
63,140 & Field strain & U.S. & JN542536 \\
CL9 & Field strain & Australia & JN804827 \\
V1-99 & Field strain & Australia & JX646898 \\
A20 & Vaccine strain & Australia & JN596963 \\
Serva & Vaccine strain & Australia & HQ630064 \\
LJ59 & Field strain & China & JX458822 \\
WG & Field strain & China & JX458823 \\
K317 & Vaccine strain & China & JX458824 \\
0206/14/Ko & Field strain & Korea & MH937564 \\
30,678/14/Ko & Field strain & Korea & MH937565 \\
40,798/10/Ko & Field strain & Korea & MH937566 \\
TCO-IVAX & Vaccine strain & U.S. & JN580312 \\
CEO-TRVX & Vaccine strain & U.S. & JN580313 \\
Gallid herpesvirus 1 & N/A & N/A & NC006623 ${ }^{a}$ \\
\hline NAA Not applicab & & &
\end{tabular}

N/A Not applicable

${ }^{a}$ The ILTV DNA sequence was assembled from 14 published ILTV sequences [36]

\section{Conclusions}

This study demonstrated the presence of ILTV in poultry farms in Myanmar. Genetic characterization of the ICP4, gB, gG, and gJ genes indicated that these isolates were different from vaccine strains and seemed to be field strains circulating in Myanmar. Phylogenetic analysis revealed that these isolates clustered together in a single branch and were closely related to other reference strains, in particular Asian isolates. These results provide some fundamental data for epidemiological studies monitoring the spread of ILTV in Myanmar.

\section{Methods}

\section{Sample collection}

Sample collection was conducted as previously reported at 20 chicken farms located in three major poultryfarming areas in Myanmar, namely Mandalay, Pyin Oo Lwin, and Yangon [20]. Briefly, oropharyngeal swabs were collected from five farms in Mandalay and five farms in Pyin Oo Lwin in February 2018, and ten farms in Yangon in May 2018. In each farm, swab samples were collected from six, nine, or twelve adult laying hens whose breeds were Rhode Island Red or White Leghorn (Table 1). The laying hens in these 20 farms were immunized with ILTV live vaccine (LT-IVAX strain) at the age of 10 weeks. All samples were transferred to the laboratory at $4{ }^{\circ} \mathrm{C}$ within 2 days of swab collection and were then stored at $-80^{\circ} \mathrm{C}$ until use.

\section{DNA extraction and molecular detection of ILTV}

Three swab samples were pooled (Table 1) and DNA was extracted using a QIAamp DNA Mini Kit (Qiagen, Hilden, Germany) according to the manufacturer's instructions. The extracted DNA samples were stored at $20^{\circ} \mathrm{C}$ until use.

The thymidine kinase (TK) gene of ILTV was targeted for the detection of ILTV by PCR using previously published primers (Table 4) [35]. The PCR mixture contained $10 \mathrm{pmol}$ of each primer, $1 \mathrm{U}$ of TaKaRa Ex Taq (TaKaRa Bio Inc., Kusatsu, Japan), and $200 \mu \mathrm{M}$ of each deoxynucleotide (TaKaRa Bio Inc.). The DNA sample obtained from an attenuated ILTV live vaccine (LTIVAX strain) (Kyoritsu Seiyaku Corporation) was used as a positive control.

\section{Genetic characterization of ILTV}

DNA samples positive for TK gene were subjected to sequencing analysis of $I C P 4, g B, g G$, and $g J$ genes. For each gene, the regions in which the polymorphisms are typically observed among ILTV strains were partially amplified by PCR (Table 4) [21]. For sequencing, the amplified DNA products were purified using a FastGene gel/PCR extraction kit (NIPPON Genetics Co. Ltd.), and the nucleotide sequences were determined using the GenomeLab $^{\text {tw }}$ GeXP Genetic Analysis System (Beckman Coulter, Fullerton, CA, USA). The obtained sequences of the ICP4, $g B, g G, g J$ genes were aligned with reference sequences from GenBank database (Table 5) using MEGA6 software [37] and the phylogenetic trees were generated with the same software using the neighborjoining method coupled with Kimura 2-parameter model with bootstrap analysis of 1000 replicates [38].

\section{Supplementary Information}

Supplementary information accompanies this paper at https://doi.org/10 1186/s12917-020-02666-z.

Additional file 1: Table S1. Nucleotide sequence alignment of Tk gene fragments from the isolates in Myanmar, vaccines strains and other ILTV

strains. Table S2. Defined haplotype according to gJ amplified sequence.

\section{Abbreviations}

CEO: Chicken embryo-origin; GaHV-1: Gallid alphaherpesvirus 1; ILTV: Infectious laryngotracheitis virus; ILT: Infectious laryngotracheitis; PCR: Polymerase chain reaction; SNP: Single nucleotide polymorphisms; TCO: Tissue culture-origin; TK: Thymidine kinase

\section{Acknowledgements}

We thank all the farmers and veterinarians who kindly helped with sample collection. We thank Drs. Masayoshi Isezaki, Tomohiro Okagawa, and Naoya Maekawa, Faculty of Veterinary Medicine, Hokkaido University, Sapporo, Japan, for their helpful advice. We would like to thank Editage (www.editage. jp) for English language editing. This research was supported in part by Grants-in-Aid for Scientific Research (B: $16 \mathrm{H} 05804$ and B: 18H02332) and a 
Young Scientists grant (B: 16 K18798) from the Japan Society for the Promotion of Science.

\section{Authors' contributions}

$Z Y, S M$, and SF were responsible for the conception and design of the study. SM, MT, KK, MMH, and SYW collected samples. MMH, SYW, and SB obtained the informed consent from farm owners before the sample collection and performed all the procedures for sample collection in Myanmar. ZY, SM, SF, and MT performed the experiments. ZY, SM, and SF analysed the data. SM, SK, and KO provided intellectual input, laboratory materials, reagents and analytic tools. ZY and SM wrote the manuscript. ZY, SM, KK, SB, SK, and KO revised the manuscript. All authors reviewed and approved the final manuscript.

\section{Funding}

This research was supported in part by Grants-in-Aid for Scientific Research (B: $16 \mathrm{H} 05804$ and B: 18H02332) and a Young Scientists grant (B: 16 K18798) from the Japan Society for the Promotion of Science. All of the funding bodies were applied to sample collection, data analysis and interpretation, and writing the manuscript.

\section{Availability of data and materials}

The datasets analysed during the current study are available in the the National Center for Biotechnology Information (NCBI) repository, accession numbers: LC592178-213.

\section{Ethics approval and consent to participate}

Swab samples used in this study had obtained based on written informed consent from farm owners. Collection of swab samples from chickens was approved by the Ministry of Agriculture, Livestock and Irrigation of Myanmar (approval number: 5/6000/moali (1192/2017) and 1080/pa10(kha)/2017).

\section{Consent for publication}

Not applicable.

\section{Competing interests}

The authors declare that they have no competing interests.

\section{Author details}

${ }^{1}$ Faculty of Veterinary Medicine, Hokkaido University, Sapporo, Japan. ${ }^{2}$ Institute of Animal Husbandry and Veterinary Medicine, Beijing Academy of Agriculture and Forestry Sciences, Beijing, China. ${ }^{3}$ University of Veterinary Science, Yezin, Nay Pyi Taw, Myanmar.

Received: 10 February 2020 Accepted: 4 November 2020 Published online: 23 November 2020

\section{References}

1. Craig Ml, Rojas MF, van der Ploeg CA, Olivera V, Vagnozzi AE, Perez AM, et al. Molecular characterization and cluster analysis of field isolates of avian infectious Laryngotracheitis virus from Argentina. Front Vet Sci. 2017;4:212.

2. Davison AJ. Herpesvirus systematics. Vet Microbiol. 2010;143(1):52-69.

3. García M, Spatz S, Guy JS. Infectious laryngotracheitis. In: Swayne DE, Glisson $J R$, McDougald LR, Nolan LK, Suarez DL, Nair V, editors. Diseases of Poultry. 13th Ed. Ames, lowa: Blackwell Publishing; p. 161-79.

4. Garcia M. Current and future vaccines and vaccination strategies against infectious laryngotracheitis (ILT) respiratory disease of poultry. Vet Microbiol. 2017;206:157-62.

5. Samberg Y, Cuperstein E, Bendheim U, Aronovici I. The development of a vaccine against avian infec tious laryngotracheitis. IV. Immunization of chickens with a modified laryngotracheitis vaccine in the drinking water. Avian Dis. 1971;15(2):413-7.

6. Gelenczei EF, Marty EW. Studies on tissue-culture-modified infectious Laryngotracheitis virus. Avian Dis. 1964;8(1):105-22.

7. Guy JS, Barnes HJ, Smith L. Increased virulence of modified-live infectious laryngotracheitis vaccine virus following bird-to-bird passage. Avian Dis. 1991;35(2):348-55.

8. Menendez KR, Garcia M, Spatz S, Tablante NL. Molecular epidemiology of infectious laryngotracheitis: a review. Avian Pathol. 2014;43(2):108-17.

9. Piccirillo A, Lavezzo E, Niero G, Moreno A, Massi P, Franchin E, et al. Full genome sequence-based comparative study of wild-type and vaccine strains of infectious laryngotracheitis virus from Italy. Plos One. 2016;11(2): e0149529.

10. La TM, Choi EJ, Lee JB, Park SY, Song CS, Choi IS, et al. Comparative genome analysis of Korean field strains of infectious laryngotracheitis virus. PLoS One. 2019;14(2):e0211158.

11. Agnew-Crumpton R, Vaz PK, Devlin JM, O'Rourke D, Blacker-Smith HP, Konsak-llievski B, et al. Spread of the newly emerging infectious laryngotracheitis viruses in Australia. Infect Genet Evol. 2016;43:67-73.

12. Kong C, Zhao Y, Cui X, Zhang X, Cui H, Xue M, et al. Complete genome sequence of the first Chinese virulent infectious laryngotracheitis virus. PLoS One. 2013;8(7):e70154.

13. Moreno A, Piccirillo A, Mondin A, Morandini E, Gavazzi L, Cordioli P. Epidemic of infectious laryngotracheitis in Italy: characterization of virus isolates by PCR-restriction fragment length polymorphism and sequence analysis. Avian Dis. 2010;54(4):1172-7.

14. Lee SW, Markham PF, Coppo MJC, Legione AR, Markham JF, Noormohammadi $\mathrm{AH}$, et al. Attenuated vaccines can recombine to form virulent field viruses. Science. 2012;337(6091):188.

15. Blacker HP, Kirkpatrick NC, Rubite A, O'Rourke D, Noormohammadi AH. Epidemiology of recent outbreaks of infectious laryngotracheitis in poultry in Australia. Aust Vet J. 2011:89(3):89-94.

16. Kirkpatrick NC, Mahmoudian A, O'Rourke D, Noormohammadi AH. Differentiation of infectious laryngotracheitis virus isolates by restriction fragment length polymorphic analysis of polymerase chain reaction products amplified from multiple genes. Avian Dis. 2006;50(1):28-34.

17. Lin TN, Nonthabenjawan N, Chaiyawong S, Bunpapong N, Boonyapisitsopa S, Janetanakit T, et al. Influenza A(H9N2) Virus, Myanmar, 2014-2015. Emerg Infect Dis. 2017;23(6):1041-3.

18. Henning J, Morton J, Hla T, Meers J. Mortality rates adjusted for unobserved deaths and associations with Newcastle disease virus serology among unvaccinated village chickens in Myanmar. Prev Vet Med. 2008;85(3-4):241-52.

19. Saito T, Uchida Y, Myint WW, Thein WZ, Watanabe C, Takemae N, et al. Characterisation of highly pathogenic avian influenza viruses in Myanmar. Vet Rec. 2008;163(24):722-3.

20. Fujisawa S, Murata S, Takehara M, Katakura K, Hmoon MM, Win SY, et al. Molecular detection and genetic characterization of mycoplasma gallisepticum, Mycoplama synoviae, and infectious bronchitis virus in poultry in Myanmar. BMC Vet Res. 2019:15(1):261.

21. Chacon JL, Ferreira AJP. Differentiation of field isolates and vaccine strains of infectious laryngotracheitis virus by DNA sequencing. Vaccine. 2009; 27(48):6731-8.

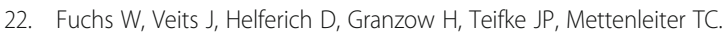
Molecular biology of avian infectious laryngotracheitis virus. Vet Res. 2007; 38(2):261-79.

23. Choi EJ, La TM, Choi IS, Song CS, Park SY, Lee JB, et al. Genotyping of infectious laryngotracheitis virus using allelic variations from multiple genomic regions. Avian Pathol. 2016;45(4):443-9.

24. Spatz SJ, Garcia M, Riblet S, Ross TA, Volkening JD, Taylor TL, et al. MinION sequencing to genotype US strains of infectious laryngotracheitis virus. Avian Pathol. 2019;48(3):255-69.

25. Johnson MA, Tyack SG, Prideaux C, Kongsuwan K, Sheppard M. Nucleotidesequence of infectious Laryngotracheitis virus (Gallid Herpesvirus-1) Icp4 gene. Virus Res. 1995;35(2):193-204.

26. Chang PC, Lee YL, Shien JH, Shieh HK. Rapid differentiation of vaccine strains and field isolates of infectious laryngotracheitis virus by restriction fragment length polymorphism of PCR products. J Virol Methods. 1997;66(2):179-86.

27. Connolly SA, Jackson JO, Jardetzky TS, Longnecker R. Fusing structure and function: a structural view of the herpesvirus entry machinery. Nat Rev Microbiol. 2011:9(5):369-81.

28. Garcia M, Volkening J, Riblet S, Spatz S. Genomic sequence analysis of the United States infectious laryngotracheitis vaccine strains chicken embryo origin (CEO) and tissue culture origin (TCO). Virology. 2013:440(1):64-74.

29. Mundt A, Mundt E, Hogan RJ, Garcia M. Glycoprotein J of infectious laryngotracheitis virus is required for efficient egress of infectious virions from cells. J Gen Virol. 2011;92:2586-9.

30. Han MG, Kim SJ. Analysis of Korean strains of infectious laryngotracheitis virus by nucleotide sequences and restriction fragment length polymorphism. Vet Microbiol. 2001;83(4):321-31.

31. Devlin JM, Browning GF, Hartley CA, Kirkpatrick NC, Mahmoudian A, Noormohammadi AH, et al. Glycoprotein $\mathrm{G}$ is a virulence factor in infectious laryngotracheitis virus. J Gen Virol. 2006;87:2839-47. 
32. Devlin JM, Viejo-Borbolla A, Browning GF, Noormohammadi AH, Gilkerson JR, Alcami A, et al. Evaluation of immunological responses to a glycoprotein $G$ deficient candidate vaccine strain of infectious laryngotracheitis virus. Vaccine. 2010;28(5):1325-32.

33. Oldoni I, Rodriguez-Avila A, Riblet S, Garcia M. Characterization of infectious Laryngotracheitis virus (ILTV) isolates from commercial poultry by polymerase chain reaction and restriction fragment length polymorphism (PCR-RFLP). Avian Dis. 2008;52(1):59-63.

34. Shehata AA, Halami MY, Sultan HH, Abd El-Razik AG, Vahlenkamp TW. Chicken embryo origin-like strains are responsible for infectious laryngotracheitis virus outbreaks in Egyptian cross-bred broiler chickens. Virus Genes. 2013;46(3):423-30.

35. Pang YS, Wang H, Girshick T, Xie ZX, Khan MI. Development and application of a multiplex polymerase chain reaction for avian respiratory agents. Avian Dis. 2002;46(3):691-9.

36. Thureen DR, Keeler CL Jr. Psittacid herpesvirus 1 and infectious laryngotracheitis virus: comparative genome sequence analysis of two avian alphaherpesviruses. J Virol. 2006;80(16):7863-72.

37. Tamura K, Stecher G, Peterson D, Filipski A, Kumar S. MEGA6: molecular evolutionary genetics analysis version 6.0. Mol Biol Evol. 2013;30(12):2725-9.

38. Felsenstein J. Confidence-limits on phylogenies - an approach using the bootstrap. Evolution. 1985:39(4):783-91.

\section{Publisher's Note}

Springer Nature remains neutral with regard to jurisdictional claims in published maps and institutional affiliations.

Ready to submit your research? Choose BMC and benefit from:

- fast, convenient online submission

- thorough peer review by experienced researchers in your field

- rapid publication on acceptance

- support for research data, including large and complex data types

- gold Open Access which fosters wider collaboration and increased citations

- maximum visibility for your research: over $100 \mathrm{M}$ website views per year

At $\mathrm{BMC}$, research is always in progress.

Learn more biomedcentral.com/submissions 